\title{
ME'AI

\section{THE USE OF THERMOVISION FOR THE ANALYSIS OF SHEET DEFORMATION}

\author{
Krzysztof ŻABA, Kamil ZOŁA, Sandra PUCHLERSKA, Dariusz LEŚNIAK \\ AGH University of Science and Technology, Cracow, Poland, EU, \\ krzyzaba@agh.edu.pl, kamillo0988@gmail.com, spuchler@agh.edu.pl, dlesniak@agh.edu.pl
}

https://doi.org/10.37904/metal.2019.861

\begin{abstract}
Each metal is characterized by its typical stacking-fault energy (SFE). The higher this energy is, the less often are stacking errors in the crystal lattice. The stacking-fault energy has a large influence on the behavior of the metal during plastic deformation, which is mainly related to the relationship between SFE and the dislocation ability for climbing and lateral slip. The measurement of deformations is usually performed in a uniaxial tension test. In order to determine the deformations in real time, GAMA's ARAMIS system is used, which is non-contact and is independent of the tested material. Its operation involves the use of digital image correlation. An interesting solution seems to be the use of thermovision to measure deformation by analyzing thermographic images during stretching of materials. The aim of the study was a comparative analysis of the results obtained by measuring strains using the ARAMIS system and temperature using a FLIR thermal imaging camera. Samples cut from sheets of aluminium, copper and steel alloys were designated for testing. In the first frame, the most favorable way of preparing the surface of the plates was determined in order to obtain reliable temperature measurements by increasing the emissivity factor. The samples were then stretched. Then a correlation was made between the temperature and the deformation for a given material. The results allow us state that thermovision can be successfully used in the future to measure material deformations.
\end{abstract}

Keywords: Termovision, 3D scanning

\section{INTRODUCTION}

Nowadays, vision systems used for the analysis and testing of material deformations are used more and more often. Devices based on non-contact measurement methods gain more and more popularity due to their ease of use, accuracy and versatility in making measurements. One of the systems used to measure displacements, stresses in structure and deformation is ARAMIS (GOM) [1]. This system documents and calculates deformations. It works by recording subsequent frames during deformation. The system then compares the digitized images, calculates the displacement and deformation of the object's characteristics. To accomplish this, characteristic points must be found on the surface of the material to be tested, thanks to which coordinates will be assigned to the corresponding pixels of the image. In the case of testing of homogeneous surfaces, the surfaces before the test should be prepared by applying a suitable spray that gives the test surface the relevant characteristic points [2]. Thermovision is a non-destructive testing method that allows you to study the distribution of temperature on the body surface in a non-destructive manner. Measurements that using thermovision can be the applied because of existence of infrared radiation, which is emitted by examined body. One of the biggest advantages of thermovision tests is the possibility of obtaining an immediate reading of measurement results [3]. Thermal imaging tests involve the detection of infrared radiation by the measuring device (infrared camera), which is an electromagnetic wave [4]. Thermovision studies can be divided into two main categories: passive and active thermovision. Passive thermovision is based on the study of the temperature distribution of the object created as a result of its functioning. In the case of active thermovision, we examine the temperature field of the object created as a result of intentional thermal stimulation of the object. The tested object can be thermally stimulated by a stream of cold or hot air, IR radiators, vibrations. [5]. Thermovision is widely used in many industries. In the chemical industry, it is used to assess the technical condition of the installation. It allows notice defects already in the early frames of their formation. In 
construction, it is used to assess the thermal insulation of buildings. Thanks to it, it is possible to detect defects in thermal insulation and allows for the compliance of the applied materials with the materials required by the project. It is also used to analyse the efficiency of machines. Analysis and comparison of the thermograms of the damaged and functional machine gives the opportunity to find the source of the machine's fault. It is also used in medicine. It is used for retinal examination and for the diagnosis of eyeball tumors. [6]. Conducted research was focused on the possibilities of measuring deformation of the tested material by observing its thermal stimulation during a static tensile test. It is predicted that in materials with high stacking fault energy it is possible to measure the deformation only on the basis of thermal energy released by the material during its deformation

\section{METODOLOGY}

The first step before starting the research was to prepare the appropriate samples. They have been cut from an aluminium sheet $6013 \mathrm{t} 4$ sheet with dimensions d0 $=15 \mathrm{~mm}, \mathrm{LO}=80 \mathrm{~mm}$. Subsequently, the surface of the samples was prepared. It consisted in covering samples with a special spray, thanks to which measuring points were applied on their surface - see Figure 1 and Figure 2.

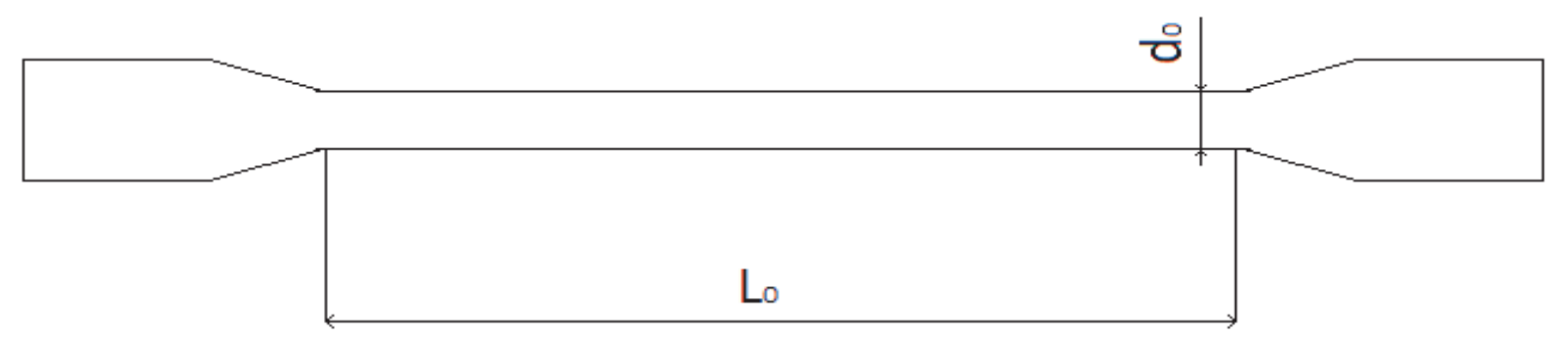

Figure 1 Sample scheme

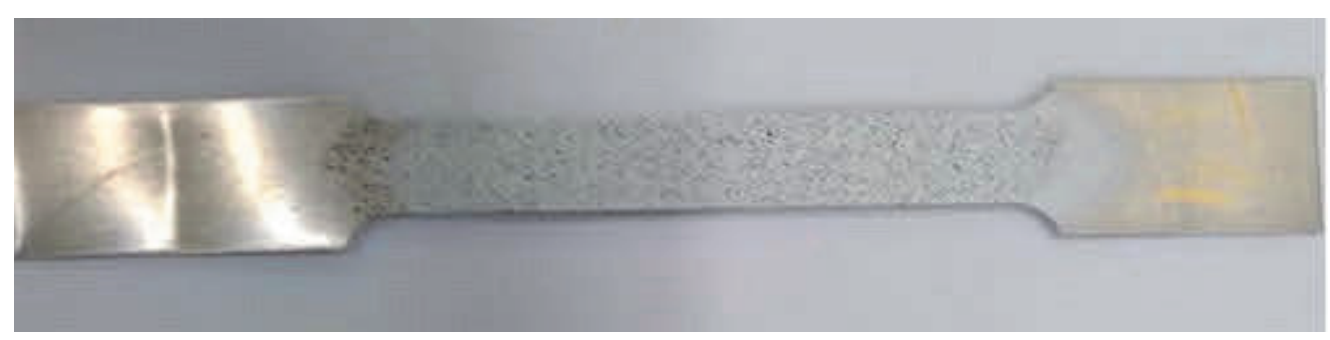

Figure 2 Sample after spraying with a spray

ARAMIS system was calibrated accordingly. For this purpose, the resolution of the scanner's cameras was set to the maximum value first. The calibration consists in the execution of a series of images on the calibration panel. The first step is to place the panel near the place where the tests will be performed. Then the scanner's cameras must be centered and focused on the panel. After this operation, the cameras must be blocked. Each of movements during testing may lead to errors in the calculations [7]. The next step is to calibrate the software by implementing the dimensions of the tested sample.

The testing machine was then calibrated using calibration panel [8] - see Figure 3. The deformation speed has been set to $60[\mathrm{~mm} / \mathrm{min}]$. Behind the scanner, the Flir T640 thermal imaging camera connected to the computer was set up to record data. The samples were then successively mounted in the jaws of the testing machine and subjected to a static tensile test. The entire process was recorded with both a thermovision camera and a scanner. The end of the test is the moment of the sample breaking. Next, the set strains were calculated using the ARAMIS system software and the results of the thermal imaging camera were developed. The final frame was to compare and compare all obtained results. It consisted in comparing a single frame 
from the ARAMIS system and the corresponding frame from the thermal imaging camera. The step for the first change was 60 frames and for the last 50 frames. The remaining steps were 100 frames. The research stand consisted of: Endurance machine, FLIR T640 thermal imaging camera, laptop, ARAMIS system.

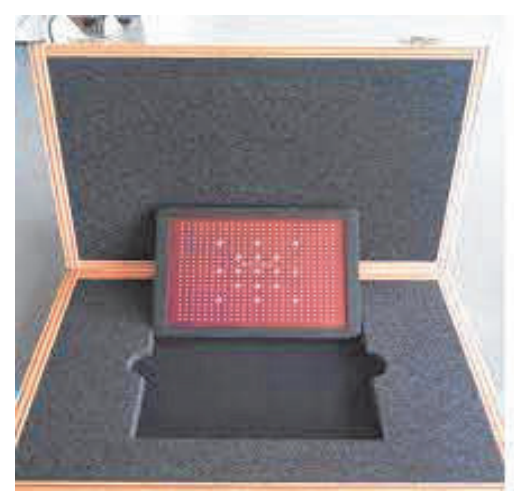

Figure 3 Calibration panel [8]

\section{RESULTS AND DISSCUSION}

Tests carried out in accordance with the above methodology allowed to obtain results in the form of a comparison of selected frames registered by the ARAMIS system and a thermal imaging camera.

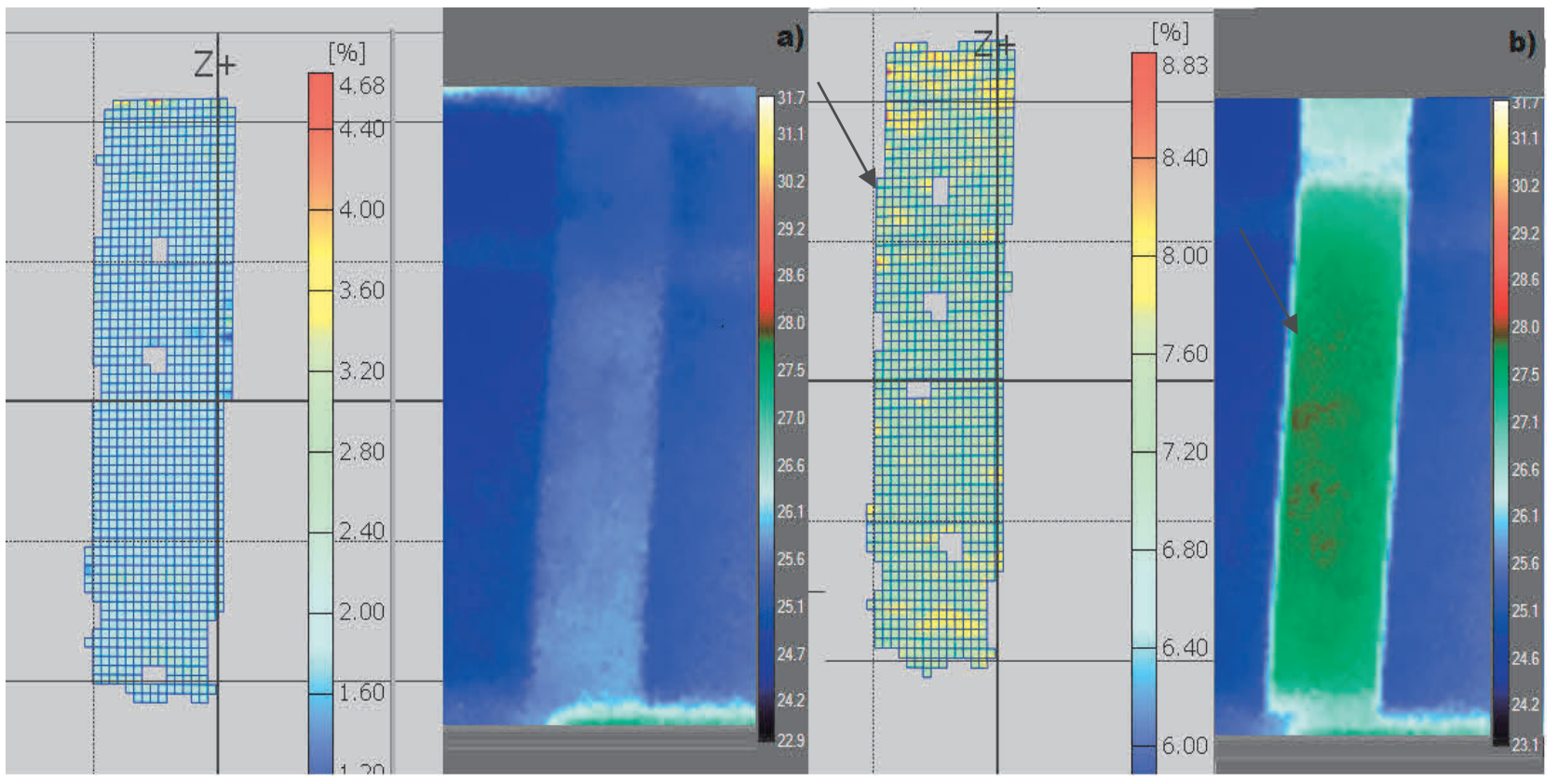

Figure 4 Comparison: ARAMIS and infrared camera for frames a) 60, b) 160

As can be seen in Figure 4 part a) in the initial frame of tensile the sample, the deformation on its whole surface is homogeneous and amounts to about $2 \%$. Thermographs cannot distinguish between more or less active places thermally. The image of the sample is out of focus due to the small thermal arousal of the sample and hence the high radiation effect of objects from the environment. In part b), the increase of the degree of deformation and the subsequent increase in the temperature of the sample visible on the thermogram can be clearly seen. The temperature increased by about $2{ }^{\circ} \mathrm{C}$, which allowed reduce the radiation effect of objects from the environment and a more accurate reading of the thermogram. You can observe areas in which the 
deformation is greater than the others by up to $2 \%$. After looking at these areas on thermographs, we can notice an increase in temperature in more distorted places. In the lower and upper part of the sample we see the areas in which the degree of deformation is the largest. However, this is not reflected in thermography. This may be due to disturbances in the readings related to the proximity of the jaws of the tensile machine.

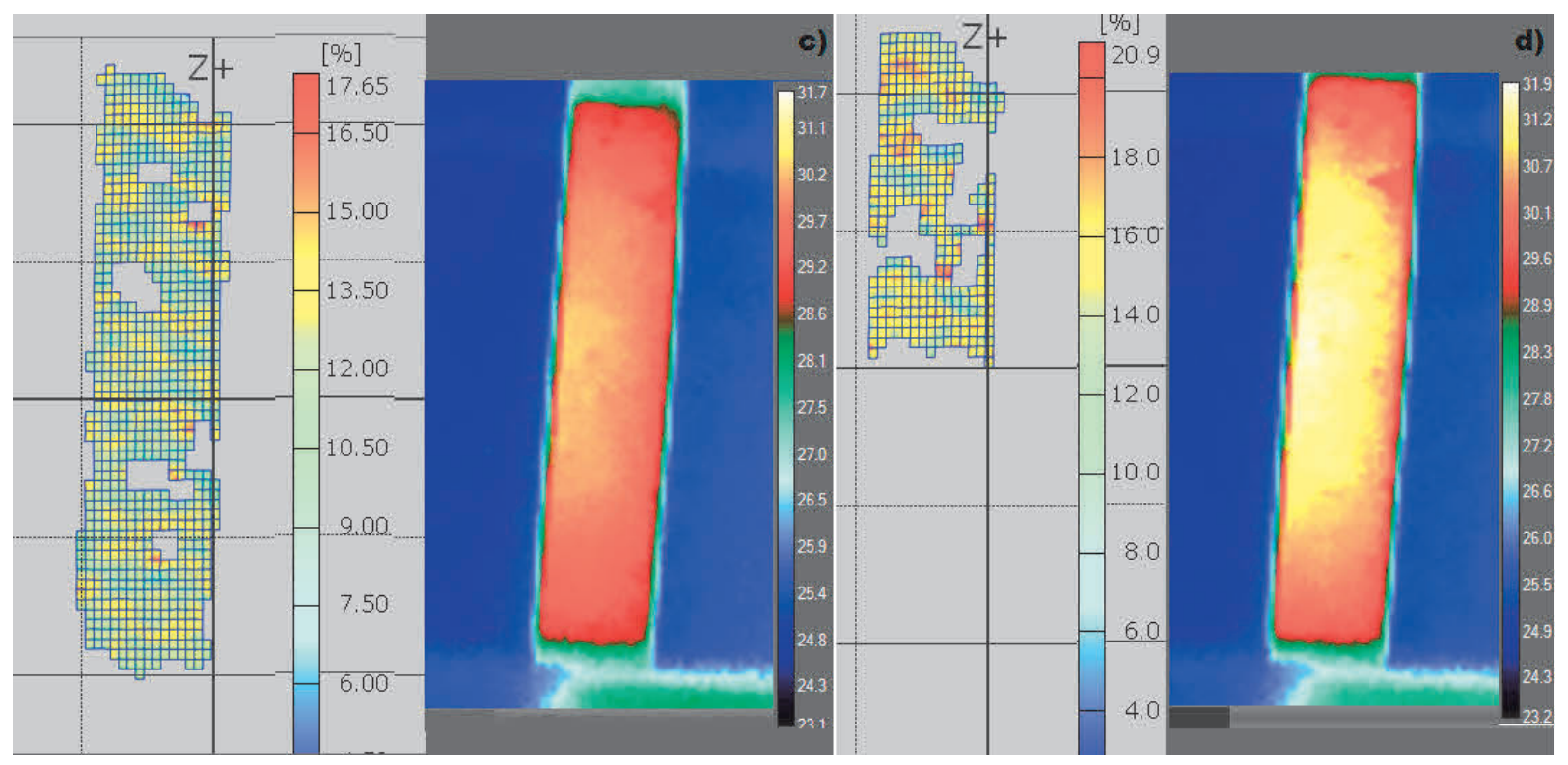

Figure 5 Comparison: ARAMIS and infrared camera for frames a) 260, b) 310

In Figure $\mathbf{5}$ in part $\mathbf{c}$ ) it can be seen that the strain measured by the ARAMIS system is about $13 \%$ and only in a few areas is higher. The thermogram shows that the temperature of the test sample also increased as the deformation increased. From about $27.5^{\circ} \mathrm{C}$ in frame b) to about $30^{\circ} \mathrm{C}$ in frame $\mathrm{C}$ ). In Figure $5 \mathrm{~d}$ ), we can see that the grid consisting of characteristic points has been damaged and is no longer visible to the scanner. Observing its residue, we can further increase the deformation of the sample and the associated increase in temperature visible on the thermogram. Here we observe the relation between the degree of deformation and the temperature of the tested sample. Due to the damage of the characteristic point grid, the analysis of further frames is no longer possible, so the analysis of the results is terminated on frame 310 .

\section{SUMMARY}

The analysis of the test results indicates the existence of a connection between the deformation and the temperature emitted by the sample. It can be observed that the temperature increases with increasing strain. In the initial frames of deformation, the thermal imaging camera is able to detect the thermal effect of even local deformations. This gives the opportunity to measure the deformation based on the thermal arousal that occurs when the material is deformed. However, further tests are necessary to improve the research methodology. An important aspect is to maintain the characteristic point grid on the sample until it breaks. This will allow explore the entire process, not just parts of it.

\section{REFERENCES}

[1] UHL, T., KOHUT, P. and HOLAK, K. Zastosowanie metod wizyjnych do monitorowania stanu konstrukcji. PAK. 2010. vol. 56, no. 6, pp. 22-24.

[2] GOM GmbH. ARAMIS v 6.1 and higher manual, 2009.

[3] HULEWICZ, A. Diagnostyka Termowizyjna w Elektrotechnice. Academic Journal.of Poznań University. 2017. No. 89, pp. 259-269. 
[4] VENEGAS, P., GUEREDIAGA, J., VEGA, L., MOLLEDA, J. and BULNES, G.F. Infrared Thermography for Temperature Measurement and Non-Destructive Testing. Journal Sensors, 2014. vol 14, pp 1235-1248.

[5] MALDAGUE, X.P.V. Nondestructive Evaluation of Materials by Infrared Thermography, pp 3-11.

[6] MADURA, H; Pomiary termowizyjne w praktyce. 1st ed. Poznań: Agenda Wydawnicza PAKu, 2014. P. 128. .

[7] PICKERD, V. Optimisation and Validation of the ARAMIS Digital Image Correlation System for use in Large-scale High Strain-rate Events. $1^{\text {st }}$ ed. Fishermans Bed: DSTO, 2013, p. 30.

[8] QIJUN, Hu., XIAOQIANG, Y., QIJIE, C. and CHAO, H. Application of ARAMIS Digital Speckle In Clay Interlayer Deformation Measurement, EJGE. 2015. vol. 20, pp. 287-300. 